\title{
A Psicologia na Articulação entre os Âmbitos Coletivo e Psíquico: Construção de Uma Política Pública em Saúde de Cuidado com o Desenvolvimento
}

Psychology In The Articulation Between The Psychic And Collective Spheres: Building A Public Policy In Health Care With The Development

La Psicología En La Articulación Entre Los Ámbitos Colectivo Y Psíquico: Construcción De Una Política Pública En Salud De Cuidado Con El Desarrollo

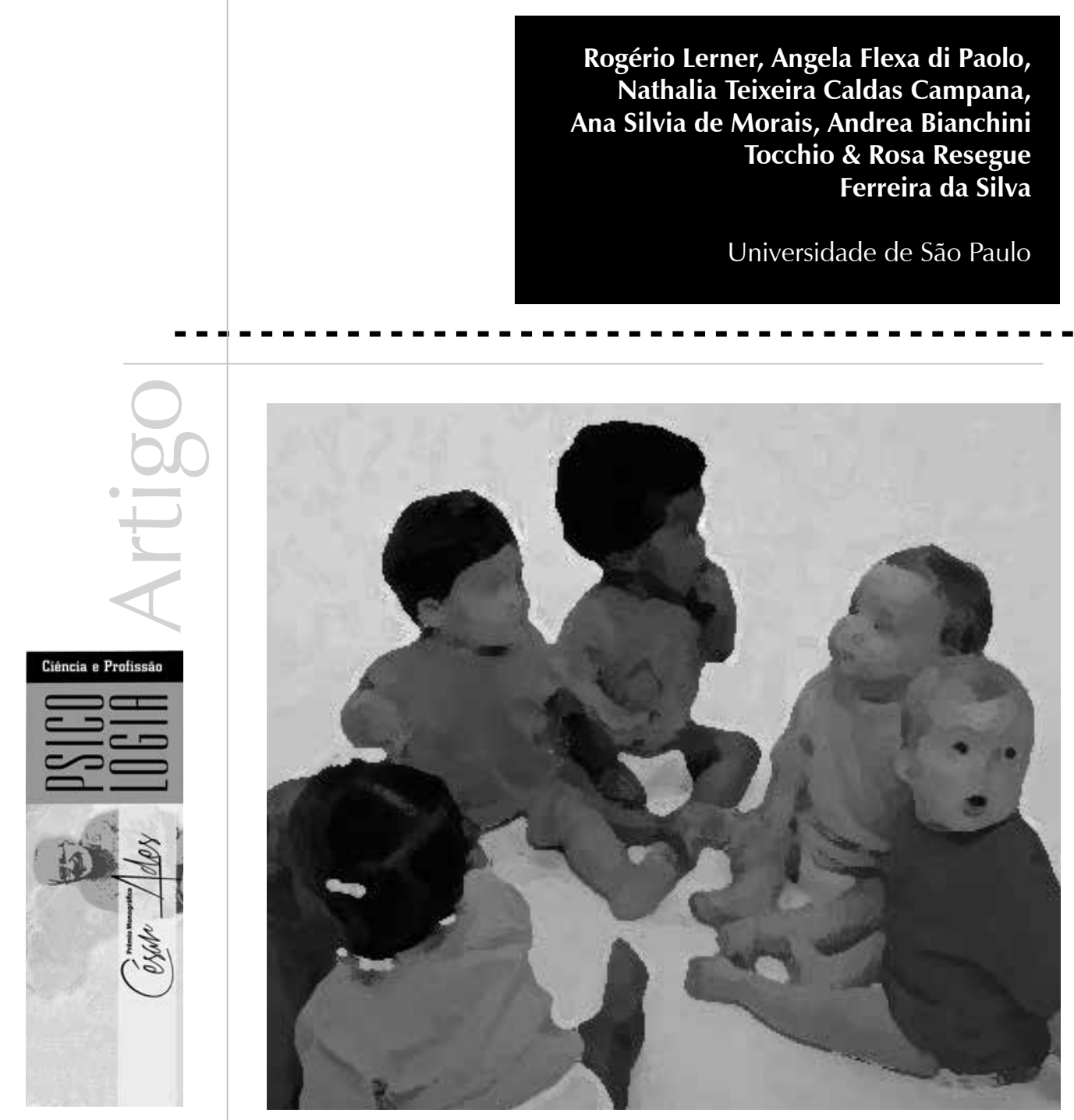


Resumo: Contemporaneamente, demanda-se que a Psicologia contribua com políticas públicas em saúde operando a articulação entre os âmbitos coletivos e psíquicos. Os Indicadores Clínicos de Risco para o Desenvolvimento Infantil - IRDI podem fazê-lo desde a atenção básica por considerar o desenvolvimento como decorrente da interação entre organismo e relacionamentos vividos pelo bebê. Seus itens são circunstâncias cotidianas nas quais subjazem operações psíquicas fundamentais para o desenvolvimento. A realidade do Sistema Único de Saúde impõe à Psicologia o imperativo ético de se questionar quanto à versão de psiquismo que se constrói em cada atendimento, psicológico ou não, para o qual um psicólogo contribui. Essa demanda depende da articulação entre os âmbitos coletivos e psíquicos na construção de uma política pública em saúde de cuidado com o desenvolvimento. A experiência dos profissionais de atenção básica, ao se apropriarem dos indicadores do IRDI e de seus fundamentos, é de ampliação da abertura para a singularidade das pessoas envolvidas na avaliação e na orientação realizadas.

Palavras-chave: Psicanálise. Políticas públicas. Detecção de sinal (Percepção). Formação dos profissionais de saúde.

\begin{abstract}
Nowadays, psychology has been demanded to contribute with health public polices articulating collective and psychic stances. The Clinical Indicators of Risk for the Infantile Development - IRDI can achieve it in the context of primary attention for considering development as derived of the interaction between organism and relationships experienced by the baby. Its items are everyday circumstances in with underpin psychic operations that are core for development. The reality of the Brazilian Unique System of Health imposes to psychology the ethic imperative of questioning itself in regard to the version of the mind built in every consultation, psychological or otherwise, which receives the contribution of a psychologist. This demand depends on the articulation between the collective and psychic fields in building a public health policy of development care. The experience of primary care professionals who get to know the items of the protocol and their fundaments increases the overture for the singularity of the people involved in the assessments and orientation provided.
\end{abstract}

Keywords: Psychoanalysis. Public policies. Signal detection (Perception). Health professionals' education.

Resumen: Contemporáneamente, se demanda que la Psicología contribuya con políticas públicas en salud operando la articulación entre los ámbitos colectivo y psíquico. Los Índices Clínicos de Riesgo para el Desarrollo Infantil - IRDI pueden hacerlo a partir de la atención básica por considerar el desarrollo como consecuencia de la interacción entre el organismo y las relaciones vividas por el bebé. Sus ítems son circunstancias cotidianas en las cuales subyacen operaciones psíquicas fundamentales para el desarrollo. La realidad del Sistema Único de Salud le impone a la Psicología el imperativo ético de cuestionarse en relación a la versión de psiquismo que se construye en cada servicio, psicológico o no, para el cual un psicólogo contribuye. Esa demanda depende de la articulación entre los ámbitos colectivo y psíquico en la construcción de una política pública en salud de cuidado con el desarrollo. La experiencia de los profesionales de atención básica, al apropiarse de los índices del IRDI y de sus fundamentos, es de ampliación de la apertura para la singularidad de las personas involucradas en la evaluación y en la orientación realizadas.

Palabras clave: Psicoanálisis. Políticas públicas. Detección de señal (Percepción). Formación de los profesionales de salud.

Os autores agradecem à Fundação de Amparo à Pesquisa do Estado de São

Paulo e à Fundação Maria Cecília Souto Vidigal pelo financiamento da pesquisa. convocam o psicólogo a assumir um lugar de perito em normatizar e naturalizar fenômenos humanos, de forma a elidi-los do âmbito da cultura (Cruz, Hillesheim, \& Guareschi, 2005). Nos mais das vezes, a Psicologia acabou por consolidar políticas de exclusão em vez de contribuir para tornar mais complexas as formas de cuidado da população, sofisticando-as. então em políticas públicas em saúde a partir de concepções de sujeito abstratas que acabam por ficar destituídas de dimensão política (Benevides, 2005), o que se reforça por diversos dispositivos institucionais que
Oliveira, Neto, Maia Pinto, Silva e Jorge sustentam que políticas públicas devem ser propostas considerando "conhecimentos 
Segundo

Ferreira Neto,

Kind, Barbosa

Pereira, Rezende

e Fernandes

(2011), tendo

uma abordagem

inicial centrada

no materialismo

histórico e nas

ciências sociais,

a discussão em

saúde coletiva

ampliou-se

a partir da

referência

a diversas

concepções de

subjetividade oriundas

das ciências

humanas, com

destaque para

diferentes escolas

de Filosofia e

para a Psicologia. sobre o processo saúde-doença, reunindo distintas disciplinas que o abordam sob diferentes ângulos" (2010, p. 282). Tais autores destacaram que, por um lado, a proposta tradicional de educação em saúde agregou maior cientificidade e precisão técnica ao conhecimento; por outro, carreou uma tendência ao tecnicismo que tem levado os profissionais da saúde a desconsiderar aspectos humanos sutis e intrincados que têm influência no processo saúde-doença não contemplados pelas especialidades. Dentre as críticas endereçadas aos profissionais de saúde que se graduam, a principal relacionase ao perfil profissional tecnicista voltado para o trabalho em instituições privadas, com o consequente despreparo para lidar com a complexidade da saúde no âmbito público e coletivo (Guimarães \& Silva, 2010).

Nota-se, entretanto, a existência de uma sensibilidade para mudar o quadro enunciado acima: em pesquisa realizada por Oliveira etal. (2010) com acadêmicos de Medicina, 67,1\% dos participantes ressaltou a importância de disciplinas da saúde coletiva no seu curso, avaliando-as como bastante importantes e muito importantes; quase a totalidade dos entrevistados (90,7\%) esteve de acordo com sua inserção na grade curricular, avaliando seus conteúdos empaticamente.

Segundo Ferreira Neto, Kind, Barbosa Pereira, Rezende e Fernandes (2011), tendo uma abordagem inicial centrada no materialismo histórico e nas ciências sociais, a discussão em saúde coletiva ampliou-se a partir da referência a diversas concepções de subjetividade oriundas das ciências humanas, com destaque para diferentes escolas de Filosofia e para a Psicologia. Segundo os autores, a crescente operação do Sistema Único de Saúde no Brasil engendrou discussões nas quais a noção de subjetividade assumiu três conotações associadas entre si: constituição política dos atores sociais para o processo de reforma sanitária, consideração da dimensão da intersubjetividade no cuidado e na gestão em saúde (ou seja, destaque para o fato de que profissionais de saúde não se relacionam com objetos, mas com sujeitos) e o incremento da condição de autonomia das pessoas envolvidas.

Fleury-Teixeira et al. afirmaram que, desde os anos 80, uma corrente epidemiológica em saúde coletiva passou a evidenciar "a presença do elo psíquico nas cadeias de determinação social da saúde, demonstrando também sua crescente importância na contemporaneidade" (2008, p. 2.118). Os autores consideraram que existe uma profunda associação entre condições psíquicas e formas de interação social influenciadas por ordenamentos sociais e posições recíprocas dos indivíduos na hierarquia social, o que constitui elo fundamental incidente sobre as causas das principais circunstâncias patológicas da contemporaneidade.

A proposta de recuperação da complexidade que serve de enquadramento para o processo de saúde-doença por meio da interdisciplinaridade componente da saúde coletiva, a contribuição da noção de subjetividade para a área e o destaque dado ao psíquico no elo fundamental mencionados acima representam uma nova oportunidade de articulação com a Psicologia, pautada pelo postulado de que psiquismo, organismo e relacionamentos interpessoais têm profunda influência um sobre o outro. Ainda assim, observa-se uma quase inexistência de disciplinas de Psicologia nos cursos da área de saúde coletiva (Nunes et al., 2010).

No presente trabalho, o protocolo de Indicadores Clínicos de Risco para o Desenvolvimento Infantil - IRDI (Kupfer et al., 2010) será apresentado como uma contribuição atual da Psicologia para as políticas públicas em saúde. 


\section{Apresentação do protocolo IRDI}

O IRDI é composto por 31 itens que expressam o estado de saúde do bebê no vínculo com os pais nos primeiros 18 meses de vida. A ausência de alguns dos itens pode representar risco para o desenvolvimento da criança. Tendo sido proposto a fim de ser utilizado no âmbito da Atenção Primária em Saúde Pública, o IRDI é inespecífico quanto a diagnóstico.

O IRDI tem se prestado a inúmeras aplicações: alguns indicadores serviram de base para a construção dos itens Desenvolvendo-se com Afeto, da Caderneta da Criança adotada pela Área de Saúde da Criança do Ministério da Saúde (Brasil, 2007).

Di Paolo (2010) verificou a capacidade do IRDI para predizer qualidade de vida aos seis anos a partir de resultados obtidos no Child Health Questionnaire - CHQ-50, instrumento que apresenta dois índices sumários referentes à condição física (aspectos funcionais) e à condição psicossocial (aspectos relacionais). Os resultados da análise estatística apontaram que o IRDI tem capacidade maior para predizer diminuição na qualidade de vida relacionada ao índice psicossocial $(p=0,049)$.

Lerner (2011), utilizando um banco de dados com filmes caseiros de bebês que quando crianças tiveram diagnósticos de retardo mental, de autismo ou de desenvolvimento típico, determinou a capacidade discriminativa entre autismo, por um lado, e retardo mental e desenvolvimento típico, por outro, de diversos itens do IRDI.

Os indicadores que fazem parte do protocolo são circunstâncias recorrentes no cotidiano dos pais e dos bebês nas quais se expressam indiretamente operações psíquicas. Para que o IRDI seja aplicado, os profissionais passam por um curso no qual se explicita a ocorrência das operações psíquicas subjacentes a cada indicador e sua importância para o desenvolvimento. Dado o risco de que o IRDI seja tomado como mais uma escala de pautas a ser aplicada de forma meramente técnica, dá-se especial destaque ao sentido do seu fundamento, isto é, de que o desenvolvimento requer uma relação pessoal e emocionalmente rica para ocorrer. O contexto de aplicação dos indicadores deve tentar criar um ambiente onde os aspectos pessoais e a riqueza e a complexidade emocionais partilhados pelos pais e bebês possam ser expressos, comunicados, expostos ao trabalho com o profissional, que está, assim, em posição de cuidador. O objetivo central do curso tem sido o uso do IRDI para avaliação do desenvolvimento e para a construção de indicações que levem em conta a singularidade das pessoas envolvidas.

O curso é dividido em quatro encontros que ocorrem com intervalos de alguns meses. A cada encontro, é incentivada a manifestação pessoal dos profissionais quanto ao conteúdo de cada item do IRDI e também quanto ao seu uso na sua prática. São feitas oficinas de redescrição de cada item de acordo com a apropriação realizada pelos profissionais.

\section{Apresentação e discussão de vinhetas de aplicação do IRDI}

O IRDI tem sido aplicado em diversos contextos. As vinhetas decorrem de aplicações do protocolo feitas por profissionais de Unidades Básicas de Saúde - UBS (auxiliares de enfermagem e agentes comunitários - ACS do Programa de Saúde da Família - PSF) que passaram por curso para utilizá-los para fins de avaliação. Essas aplicações são monitoradas por psicólogos com experiência no uso do IRDI em dispositivos de Atenção Primária. Outras vinhetas decorrem de aplicações feitas por psicólogos bebês acompanhados 
em puericultura no Hospital Universitário da Universidade de São Paulo (HU) e em Centros de Atenção Psicossocial Infantis CAPSI.

Ana ${ }^{1}$ é uma auxiliar de enfermagem acostumada a acompanhar bebês e a orientar as mães. Sempre introduz nos atendimentos informações quanto à amamentação quando a criança é pequena ou quanto a quedas e acidentes domésticos quando a criança é maior e tem mais autonomia. A profissional também ensina as mães a realizarem massagens em seus bebês (Shantala). Ana passou por um curso para utilizar o IRDI e estava aplicando a quarta faixa do protocolo quando perguntou para a mãe cujo puerpério acompanhava se ela estimulava o filho de 13 meses a nomear os objetos (IRDI-29). A resposta foi negativa. A aplicação prosseguiu. No final do atendimento, o bebê apontou para a caneta que estava na sua mão e gesticulou, expressando seu desejo por pegá-la. Ana disse: - É a caneta que você quer? É? Então, fala c-a-n-e-t-a. É, c-a-n-e$t$-a. A auxiliar voltou-se para mãe e disse delicadamente: - Veja como podemos fazer quando ele pede alguma coisa. E continuou dizendo para a mãe que seria importante que ela incentivasse o filho dessa maneira para melhorar sua capacidade de se comunicar.

O objetivo do curso do qual Ana participou era sensibilizar profissionais para a relevância, no que se refere às funções psíquicas e ao desenvolvimento, de que o vínculo entre pais e bebês seja emocionalmente rico, vivido de forma a que os pais se engajem pessoalmente com o bebê, tomando-o também como uma pessoa. Além disso, buscou-se instrumentalizar profissionais para detectar os sinais de sofrimento que se expressam nesse vínculo. A cena relatada acima com Ana mostra que a sensibilização levou-a a utilizar um sinal de possível sofrimento como um elemento de indicação para a mãe que acompanhava com seu bebê.
A natureza da comunicação ocorrida com a mãe não foi impessoal como costumava ocorrer com as orientações que Ana fazia em seu trabalho.

Mariana, auxiliar de enfermagem, aplicava a terceira faixa do protocolo quando a mãe disse que não dava alimentos inteiros (IRDI22) para a criança de 11 meses. Mariana perguntou a razão, e a mãe contou que temia que a criança se engasgasse. A profissional explicou que a criança já tinha capacidade para chupar o alimento, e que só assim ele poderia fortalecer a mandíbula. Indicou que a criança já poderia comer arroz, feijão, legumes amassados, carnes desfiadas, e que era importante que a criança experimentasse coisas diferentes das que estava acostumada a comer para aprender a gostar delas.

Na aplicação da quarta faixa do protocolo, a criança veio em companhia da avó. Quando se perguntou se a criança comia bem, a avó contou que sim, e que, anteriormente, a mãe só dava comida batida, mas que recentemente havia introduzido alimentos amassados e em pequenos pedaços. A criança havia aceitado bem a mudança, comendo no mesmo prato que a mãe e a avó, costume cultural da região de fora de São Paulo de onde se originam.

A indicação feita por Mariana contemplou elementos pessoais da mãe ao levá-la a explicitar seu medo de o filho se engasgar, ao mesmo tempo em que mencionou a necessidade de que ele pudesse experimentar as comidas de que viesse a gostar, permitindo que a mãe se apropriasse da sua maneira do que foi indicado. O compartilhamento do mesmo prato da mãe e da avó, elemento cultural de ligação pessoal, familiar e íntima, reforça a natureza pessoal do contato com o menino, dando-lhe a oportunidade de estar em uma posição diversa da que tinha até então, mais de acordo com suas necessidades de desenvolvimento na ocasião. 
Andrea é uma ACS bastante envolvida no acompanhamento dos bebês, estando muito atenta a eles e discutindo as sutilezas que os indicadores do IRDI propõem. Em uma das famílias que visitou em companhia da psicóloga monitora, comentou a anotação do IRDI-12 (a mãe dá suporte às iniciativas da criança, sem poupar-lhe o esforço) como ausente. Ao detalhar sua observação, a ACS referiu-se a situações em que a mãe entregava tudo na mão da criança. Lembrouse ainda de que, na ocasião do nascimento do primeiro filho dessa família, tal tendência materna pode ter influenciado no atraso na sua fala. Andrea comentou a associação entre tais situações com a mãe, que respondeu que tinha dificuldades em antecipar as realizações da criança. A postura educativa característica das intervenções de Andrea encontra-se relativizada nessa situação, por escutar a mãe antes de prescrever uma ação e, ainda, pelo fato de a intervenção descrita ter se dado sob forte clima emocional com a ACS - evidenciada pelo tom carinhoso entre ambas e pelo conhecimento, por parte da profissional, de grande parte da rotina e do modo de cuidado dessa mãe em relação aos filhos. Na segunda aplicação do IRDI na mesma faixa desse bebê, o item 12 havia se tornado presente.

Quando a ACS Livia acompanhava uma menina de um ano com o auxílio dos indicadores da quarta faixa, notou que a fala da mãe quanto aos itens associados à imposição de regras (IRDI-26 e IRDI-30) parecia dúbia. Embora parecesse que estavam presentes, insinuava-se que apenas o pai da menina estava encarregado dessa função. Livia pedia exemplos à mãe sobre situações de proibição, para que ela falasse mais a respeito. A mãe comentou, então, que a filha não a obedecia. Ela até dizia não, mas a filha não a levava a sério, parecendo achar que era brincadeira. Já o pai, por gritar, ela obedecia. A intervenção de Livia foi: - Será que você também não leva esse 'não' na brincadeira,
Graça? A mãe riu e concordou. Seguiu-se uma conversa sobre o tom desse não e sobre a possibilidade de que a mãe negasse coisas à filha, não se sentindo obrigada a fazer tudo o que ela exigisse. Permitindo que aspectos pessoais dos pais surgissem, a dificuldade da mãe com a imposição de regras pode ser trabalhada pela ACS a partir da investigação do indicador relacionado ao assunto.

Durante uma consulta pediátrica ocorrida no HU, uma psicóloga fez a aplicação do IRDI com a mãe e Hélio, um bebê com 54 dias. A mãe estava bastante nervosa e preocupada com o peso do filho. A criança permaneceu dormindo a maior parte da consulta e despertou apenas na hora de ser examinada. A mãe dizia estar preocupada porque, quando o bebê estava prestes a completar um mês, ela havia percebido que estava sem leite. Helio chorava muito e chegou a ser internado por três dias no hospital com problemas de alimentação e de baixo peso. Perguntou-se à mãe se ela falava com a criança em um estilo particularmente dirigido a ela (IRDI-2, relativo ao manhês). A mãe respondeu não ter o hábito de falar com a criança em um estilo diferente, especialmente por andar muito nervosa e achar que o nervosismo poderia ser transmitido na fala e afetar o filho. A profissional perguntou se esse medo teria fundamento, e foi-lhe respondido que é possível que o bebê perceba quando a mãe não está bem, ressaltando-se que esse momento da fala dirigida ao filho é um momento de cumplicidade, de troca de afetos que podem ser também positivos. A pergunta que a mãe dirigiu à psicóloga demonstrou que ela foi tocada pela atenção que estava sendo dada à sua dificuldade com o bebê, de forma a confiar e a comunicar seus sentimentos. A mãe contou, então, que o bebê gostava quando o pai conversava com ele, pois o pai era mais tranquilo e cantava para ele dormir.

Em consulta com um pediatra do $\mathrm{HU}$ que já havia realizado um curso sobre o 
IRDI e sobre transtornos na infância, a mãe de Emilia, então com dez meses, buscava esclarecer algumas dúvidas sobre a alimentação da filha. O pediatra perguntou o que a criança estava comendo (questão relacionada ao IRDI-22), e a mãe disse que ela comia frutas amassadas e alguns legumes batidos no liquidificador. O médico pediu à mãe que começasse a introduzir frutas sem amassar e legumes amassados sem passar no liquidificador, para que a criança começasse a mastigar os alimentos. Em outro momento da mesma consulta, o pediatra se voltou para Emilia, que estava com a sobrancelha franzida olhando seriamente para ele, e disse: - Você tá brava? Por que você tá franzindo a sobrancelha pra mim? (comentário relacionado ao IRDI-18: A criança estranha pessoas desconhecidas para ela). Essa cena mostra como os indicadores e a importância dada ao aspecto pessoal do vínculo foram incorporados na prática clínica do pediatra.

Ângelo foi encaminhado para um Centro de Atenção Psicossocial Infantil - CAPSI a pedido da creche por não se relacionar com outras crianças e não se vincular à educadora. Na ocasião em que o IRDI foi aplicado, Ângelo tinha 18 meses de idade e estava em avaliação diagnóstica com suspeita de autismo. Enquanto a psicóloga que aplicava conversava com sua mãe a respeito do IRDI-24 (a criança suporta bem as breves ausências da mãe e reage às ausências prolongadas), o menino estava no grupo terapêutico. A mãe afirmava que o filho não reagia a sua ausência, mas, naquele momento, o bebê foi trazido até ela por estar chorando inconsolável no grupo. Ângelo olhou para a mãe, fez uma pausa em seu choro e estendeu-lhe os braços pedindo colo. A mãe acolheu o filho e ele parou de chorar. A psicóloga perguntou o que a mãe achava que tinha acabado de acontecer, e ela respondeu: - Ah, sei lá... Acho que ele estava incomodado com alguma coisa e, quando me viu, ficou calmo, mas não acho que ele estava chorando porque estava sentindo minha falta... Logo, Ângelo foi para o chão e começou a andar pela sala. Apontou para o armário e tentou abri-lo, mas estava trancado. Imediatamente, ele começou a chorar, e a mãe colocou uma mamadeira em sua boca. A psicóloga perguntou: - Por que será que Ângelo começou a chorar? A mãe sorriu e disse: - Ele queria abrir o armário, porque sabe que lá tem brinquedo; diante disso, a psicóloga perguntou por que ela havia dado a mamadeira ao filho, ao que ela sorriu sem graça e respondeu: - É mesmo, é que é tão difícil para mim ouvi-lo chorar que preferi calálo, mas assim ele não vai falar, né? Ainda nessa aplicação, a mãe disse que o filho falava ma e pa, mas que ela não sabe se isso queria dizer mamãe e papai, e, por isso, não assume que, quando ele diz ma, está chamando por ela. A psicóloga disse que ainda que não se soubesse com exatidão qual era a intenção de Ângelo, pode ser que esse ma representasse mamãe.

Na semana seguinte, a mãe pediu para conversar com a mesma psicóloga, para dizer que, depois da conversa que tiveram a respeito do desenvolvimento de Ângelo, ela havia conversado com o marido e os dois haviam mudado de atitude em relação à criança: - À noite estamos contando historinhas para ele, e agora ele já sabe contar até cinco! A aplicação do IRDI possibilitou que houvesse uma conversa com a mãe a respeito da relação estabelecida com o filho e sobre o desenvolvimento emocional da criança, favorecendo que se enriquecesse o vínculo pais-bebê.

A cena a seguir serve para ilustrar que o uso do IRDI não se reduz à aplicação do conhecimento sobre funções importantes do desenvolvimento infantil. Durante o acompanhamento de uma criança de um ano por uma ACS e pela psicóloga monitora, ambas notaram a ausência do IRDI-29 (o cuidador começa a pedir à criança que 
nomeie o que deseja, não se contentando apenas com gestos). Segundo o relato da mãe, a filha costumava apontar para o que queria ou apenas fazer barulhos. A mãe conseguia entender e atendê-la dessa maneira, pois já conhecia seus gostos e modo de se comunicar. Apesar de conhecer e de estar acostumada com as visitas domiciliares, a mãe não parecia estar muito à vontade com essa visita, falando muito pouco. Quando perguntada se não incentivava a filha falar, afirmou que ainda a achava pequena para isso. A psicóloga monitora, então, interveio no sentido de informá-la sobre a importância desse incentivo, apostando no surgimento da fala da menina. A mãe respondeu com uma pergunta, de modo muito sério: - Por acaso você é mãe? A monitora compreendeu, então, que aquela intervenção parecia ter repercutido na mãe de forma a desautorizá-la como tal, impondo um modo de ser mãe que para ela não fazia sentido. A falta de vínculo entre mãe e monitora e a maneira diretiva da intervenção podem ter sido um dos fatores que levaram à situação de impasse. Em outras palavras, não se constituiu um ambiente continente aos aspectos pessoais no bojo do qual uma indicação fosse inserida no panorama dos cuidados para com a mãe e o bebê.

\section{Discussão}

As vinhetas discutidas acima permitem pensar que a aplicação do IRDI pode auxiliar nos momentos em que a experiência pessoal da mãe é vivida com dificuldades. Winnicott argumentou que alguns procedimentos podem se constituir em maus tratos por serem uma violação da relação mãe-bebê, isso porque ambos precisam de tempo e de espaço para criar o que pode estar potencialmente entre eles, mas que requer uma construção pessoal para ser instaurado. Diante da pergunta "o que podemos fazer se não somos capazes de instruir as mães quanto a essas questões de procedimento?" (2006, p. 56), o autor sugere que evitemos interferir desnecessariamente. Podemos acrescentar que as interferências a evitar são as realizadas de forma puramente técnica, elidindo a dimensão pessoal do vínculo entre pais e bebê. Nosso conhecimento especializado deve ser submetido ao cuidado com o elemento pessoal existente nesse vínculo a fim de facilitar que os pais se encarreguem daquilo que são capazes. O que temos visto é que a aplicação do IRDI tem ensejado indicações realizadas no panorama do zelo com o elemento pessoal existente no vínculo entre pais e bebê.

Ferreira Neto et al. afirmaram que a dimensão relacional da subjetividade é um

\begin{abstract}
modo de contemplar a dimensão dialógica sempre presente nas práticas de saúde, quer reconheçamos ou não. Por isso, imersos na dimensão dialógica da existência, cabe aos profissionais de saúde criar pontes linguísticas entre o mundo tecnocientífico e o senso comum, no desenvolvimento de ações de cuidado. Além disso, as práticas de cuidado transcendem a ação de construir um objeto e intervir sobre ele, seja a doença ou mesmo o doente. Há que se considerar e construir projetos sustentáveis ampliados, que incluam a compreensão dos 'projetos de felicidade, de sucesso prático de quem quer ser cuidado'. (2011, p. 835)
\end{abstract}

Em articulação com a Psicologia, podemos considerar que a circunstância que permite a abertura para o acompanhamento da experiência vivida sob angústia representa a chance de sucesso em ser cuidado (Figueiredo, 2009), em que a função de rêverie do profissional e a consequente integração dos aspectos fragmentários, idealizados e persecutórios da pessoa assistida permitem que sejam restituídos os aspectos bons da experiência, levando à recondução de seus projetos de felicidade.

Jesus e Assis (2012) fizeram uma análise crítica das diferentes noções de acesso presentes nos 
modelos de organização dos sistemas de saúde no Brasil. Destacaram haver predominância de considerações burocráticas e assistencialistas que desconsideram a dimensão simbólica da construção social das representações de saúde-doença que envolvem profissionais e usuários. Poderíamos acrescentar que a circunstância de aplicação do IRDI pode contribuir no sentido de propor o acesso, nas práticas em saúde, a diferentes dimensões eminentemente psíquicas investigadas pela Psicologia que são simultaneamente atuantes: a existência de competências e iniciativas do bebê para se vincular aos pais, a importância de que os pais estejam em condições de interagir espontaneamente e pessoalmente com as competências e iniciativas do bebê, a sensibilização do profissional de saúde para a importância desses aspectos no desenvolvimento do bebê e dos pais, de maneira a considerar o vínculo resultante como campo tanto de expressão dos sentidos vivenciados como de constituição de novos sentidos, a instrumentalização do profissional para detectar os sinais de sofrimento que podem vir a manifestar-se nesse vínculo e o apoio ao profissional de saúde para tolerar o contato com a inexorável e necessária angústia envolvida nas interações com bebês e pais.

Muñoz-Sánchez e Bertolozzi apontaram a necessidade de que políticas públicas sejam constituídas transdisciplinariamente, dado que

a complexidade do objeto da saúde requer diferentes aportes teórico-metodológicos, sob pena de reduzir as ações a 'tarefas' pontuais, de caráter emergencial, que não modificam a estrutura da teia de causalidade. Vale enfatizar que a interpretação da saúde/doença, além de se apoiar nos processos de produção e de reprodução social, não deve descolar-se da dimensão subjetiva, que diz respeito às representações/significados que os indivíduos atribuem a fatos e à vida em si, o que acaba por refletir-se nos comportamentos e atitudes das pessoas. (2007, p. 322$)$
O curso realizado e a aplicação do IRDI podem levar o conhecimento psicológico a ter esse efeito transdisciplinar no campo da saúde, dada sua contribuição para o destaque da dimensão subjetiva e pessoal vivida na rede que envolve profissionais, pais e bebês.

Fleury-Teixeira et al. afirmaram que o ativismo em promoção de saúde necessita contemplar

o desenvolvimento de aptidões pessoais: favorecer o desenvolvimento pessoal e social proporcionando informações, educação sanitária e aperfeiçoando as aptidões pessoais indispensáveis para a vida; a reorientação dos serviços de saúde, de tal forma que transcenda a mera responsabilidade de proporcionar serviços clínicos e médicos. Esses serviços devem tomar uma nova orientação que seja sensível e respeite as necessidades culturais dos indivíduos. (2008, p. 2.119)

A Psicologia tem hoje como construir diferentes formas de contribuição para o aperfeiçoamento de aptidões pessoais indispensáveis para a vida, o que pode ser feito facilitando que profissionais de saúde exerçam suas especialidades no contexto de sensibilização para os aspectos pessoais inexoráveis das necessidades de quem é atendido.

\section{Considerações finais}

A aplicação do IRDI tem ocorrido em diversas instituições de saúde, como UBS, HU e CAPSI. Em cada uma, há uma forma particular de apropriação do instrumento por parte da equipe que se traduz na construção de políticas do cuidar. Nas UBS, a aplicação tem sido realizada por ACS e auxiliares de enfermagem que passaram por um curso no qual a complexidade da interação entre os aspectos orgânicos e relacionais do desenvolvimento é considerada 
pela abordagem do psiquismo explicitada em situações cotidianas. O destaque dado ao longo do curso para o sentido que tais situações cotidianas têm no entrelaçamento entre desenvolvimento da criança e relações estabelecidas com os pais faz com que o uso do protocolo IRDI não se reduza a mera repetição de mais uma escala a ser aplicada pelo profissional. No Município do qual as UBS fazem parte, o IRDI foi oficialmente incorporado na rotina de atenção básica por parte da Secretaria de Saúde.

As vinhetas demonstram que, após o curso, os profissionais de saúde passaram a utilizar o IRDI não só como instrumento de avaliação mas também como facilitador para a construção de indicações junto às famílias. No HU, nota-se que a aplicação geralmente ocorre na presença do pai e da mãe, que vão juntos às consultas pediátricas, ocasião em que é possível observar a ocorrência de muitos indicadores durante o exame e a conversa com o pediatra. Nos CAPSI, há predominância maior da presença materna, que vai ao lugar por uma questão de tratamento, pois um quadro já está instalado em um dos filhos. Assim, enquanto os pais que frequentam o HU levam seu bebê em consultas de puericultura, as mães que levam seus bebês para serem avaliados nos CAPSI já temem a possibilidade de risco de desenvolvimento. Essa situação exige que o aplicador esteja sensível ao temor dos pais, prestando acolhimento e, simultaneamente, informações claras quanto ao risco da criança.

A diversidade de lugares evidencia alguns benefícios proporcionados pela instrumentalização para uso dos IRDI por parte da equipe que a recebe. O IRDI permite dar uma significação a interesses e a preocupações prévios da equipe, uma sistematização de observações que, de outra maneira, ficariam soltas, e que podem passar a fundamentar o início de possíveis tratamentos com bebês em risco. Para as famílias, a aplicação e a decorrente indicação podem servir como oportunidade de cuidado e de acolhimento de sua singularidade, representando uma possibilidade de alívio quanto a algum temor de dificuldade de desenvolvimento avaliado como inexistente ou de início de trabalho quando algum sinal é detectado.

O que está em jogo é a contribuição da Psicologia para um resgate da dimensão política da subjetividade, operando por meio dos seguintes princípios (Benevides, 2005): inseparabilidade entre âmbito subjetivo e de processo coletivo de produção da realidade psíquica, autonomia e corresponsabilidade do profissional de saúde pessoalmente engajado no projeto de enodamento entre a dimensão subjetiva e a coletiva na atividade de cuidar e na transversalidade entre as áreas do conhecimento implicadas, de forma que se levantem interrogações de uma a outra com a finalidade de questionar as cristalizações de formas hegemônicas de exercício de poder.

O Sistema Único de Saúde é uma realidade que impõe à Psicologia o imperativo ético de se questionar quanto à versão de psiquismo que se constrói em cada atendimento, psicológico ou não, para o qual um psicólogo contribui. O presente e o futuro da produção de conhecimento em Psicologia e da formação de psicólogos devem estar comprometidos com esse imperativo. 


\section{Rogério Lerner}

Doutor e livre-docente em Psicologia Escolar e do Desenvolvimento Humano pela Universidade de São Paulo e docente da Universidade de São Paulo, São Paulo - SP - Brasil.

E-mail: rogerlerner@usp.br

\section{Angela Flexa di Paolo}

Doutoranda em Psicologia Escolar e do Desenvolvimento Humano na Universidade de São Paulo, São Paulo - SP - Brasil.

E-mail: angeladipaolo@usp.br

Nathalia Teixeira Caldas Campana

Mestranda em Psicologia Escolar e do Desenvolvimento Humano na Universidade de São Paulo, São Paulo - SP - Brasil.

E-mail: nacampana@gmail.com

\section{Ana Silvia de Morais}

Mestre em Psicologia Escolar e do Desenvolvimento Humano na Universidade de São Paulo, São Paulo - SP - Brasil.

E-mail: anasmorais@hotmail.com

\section{Andrea Bianchini Tocchio}

Mestre em Psicologia Escolar e do Desenvolvimento Humano na Universidade de São Paulo, São Paulo - SP - Brasil.

E-mail: andrea.bt@yahoo.com.br

\section{Rosa Resegue Ferreira da Silva}

Doutora em Pediatria pela Universidade Federal de São Paulo e docente do Departamento de Pediatria da Universidade Federal de São Paulo, São Paulo - SP - Brasil.

E-mail: rresegue@uol.com.br

\section{Endereço para envio de correspondência:}

Universidade de São Paulo, Instituto de Psicologia, Departamento de Psicologia da Aprendizagem do Desenvolvimento da Personalidade

Avenida Professor Mello Moraes, 1721, Cidade Universitária. CEP:05008-900. Caixa-postal:66261. São Paulo, SP. 


\section{Referências}

Benevides, R. (2005). A psicologia e o Sistema Único de Saúde: quais interfaces? Psicologia \& Sociedade, 17(2), 21-25. doi: http://dx.doi.org/10.1590/S0102-71822005000200004

Brasil. Ministério da Saúde. (2007). Caderneta da criança. Apostila produzida em 2007. Recuperado em 04 maio, 2012, de: http://portal.saude.gov.br/portal/arquivos/pdf/ caderneta_crianca_2007_29.pdf..

Cruz, L., Hillesheim, B., \& Guareschi, N. (2005). Infância e políticas públicas: um olhar sobre as práticas psi. Psicologia \& Sociedade, 17(3), 42-49. doi: http://dx.doi.org/10.1590/ S0102-71822005000300006

Di Paolo, A. F. (2010). Estudo exploratório dos indicadores clínicos de risco para o desenvolvimento infantil e da avaliação psicanalítica aos 3 anos para avaliar qualidade de vida e condição sintomática aos seis anos. (Dissertação de mestrado). Instituto de Psicologia, Universidade de São Paulo, São Paulo, SP.

Dimenstein, M. D. B. (1998). O psicólogo nas Unidades Básicas de Saúde: desafios para a formação e atuação profissionais. Estudos de Psicologia, 3(1), 53-81. doi: http://dx.doi. org/10.1590/S1413-294X1998000100004

Ferreira Neto, J. F., Kind, L., Pereira, A. B., Rezende, M. C. C. \& Fernandes, M. C. (2011). Usos da noção de subjetividade no campo da saúde coletiva. Cadernos de Saúde Pública, 27(5), 831-842. doi: http://dx.doi.org/10.1590/S0102$311 \times 2011000500002$

Figueiredo, L. C. M. (2009). As diversas faces do cuidar. São Paulo: Escuta.

Fleury-Teixeira, P., Vaz, F. A. C., Campos, F. C. C., Álvares, J., Aguiar, R. A. T., \& Oliveira, V. A. (2008). Autonomia como categoria central no conceito de promoção de saúde. Ciência \& Saúde Coletiva, 13(supl.2), 2115-2122. doi: http://dx.doi. org/10.1590/S1413-81232008000900016

Guimarães, D. A., \& Silva, E. S. (2010). Formação em ciências da saúde: diálogos em saúde coletiva e a educação para a cidadania. Ciência \& Saúde Coletiva, 15(5), 2551-2562. doi: http://dx.doi.org/10.1590/S1413-81232010000500029

Jesus, W. L. A., \& Assis, M. M. A. (2012). Revisão sistemática sobre o conceito de acesso nos serviços de saúde: contribuições do planejamento. Ciência \& Saúde Coletiva, 15(1), 161-170. doi: http://dx.doi.org/10.1590/S1413-81232010000100022

Kupfer, M. C. M., Jerusalinsky, N. A., Bernardino, L. M. F. Wanderlei, D. B., Rocha, P. S. B., Molina, S., et al. (2010). Predictive value of clinical risk indicators in child development: Final results of a study based on psychoanalytic theory. Revista latinoamericana de psicopatologia fundamental, 13(1), 31-52. doi: http://dx.doi.org/10.1590/S1415-47142010000100003

Lerner, R. (2011). Indicadores clínicos de risco para o desenvolvimento infantil IRDI: verificação da capacidade discriminativa entre autismo, retardo mental e normalidade. (Tese de livre-docência). Instituto de Psicologia, Universidade de São Paulo, São Paulo, SP.

Muñoz-Sánchez, A. I., Bertolozzi, M. R. (2007). Pode o conceito de vulnerabilidade apoiar a construção do conhecimento em saúde coletiva? Ciência \& Saúde Coletiva, 12(2), 319-324. doi: http://dx.doi.org/10.1590/S1413-81232007000200007

Nunes, E. D., Ferreto, L. E., Oliveira, A. L. O., Nascimento, L. J., Barros, N. F., \& Castellanos, M. E. P. (2010). O campo da saúde coletiva na perspectiva das disciplinas. Ciência \& Saúde Coletiva, 15(4), 1917-1922. doi: http://dx.doi.org/10.1590/ S1413-81232010000400007

Oliveira, J. A. A., Muniz Neto, F. J., Maia Pinto, F. J., Da Silva, M. G. C., \& Jorge, M. S. B. (2010). A transversalidade do conhecimento da saúde coletiva no currículo de medicina de uma escola médica pública: relevância das disciplinas na formação dos alunos. Revista Brasileira de Educação Médica, 34(2), 278-283. doi: http://dx.doi.org/10.1590/S010055022010000200012

Winnicott, D. W. (2006). Os bebês e suas mães. São Paulo: Martins Fontes. 